\title{
Cadmium is Acutely Toxic for Murine Hepatocytes: Effects on Intracellular Free $\mathrm{Ca}^{2+}$ Homeostasis
}

\author{
S. S. WANG ${ }^{1}$, L. CHEN ${ }^{1,2}$, S. K. XIA ${ }^{1}$ \\ ${ }^{1}$ College of Life Sciences, Nanjing Normal University, Jiangsu Province Key Laboratory for \\ Molecular and Medical Biotechnology and ${ }^{2}$ Jiangsu Engineering Research Center for Biomedical \\ Function Materials, Nanjing, China
}

Received January 26, 2006

Accepted February 27, 2006

On-line available March 23, 2006

\begin{abstract}
Summary
We studied cadmium toxicity in murine hepatocytes in vitro. Cadmium effects on intracellular free $\mathrm{Ca}^{2+}$ concentration $\left(\left[\mathrm{Ca}^{2+}\right]_{\mathrm{i}}\right)$ were assayed, using a laser scanning confocal microscope with a fluorescent probe, Fluo-3/AM. The results showed that administration of cadmium chloride $\left(\mathrm{CdCl}_{2}, 5,10,25 \mu \mathrm{M}\right)$ resulted in a dose-dependent decrease of hepatocyte viability and an elevated aspartate aminotransferase (AST) activity in the culture medium ( $<<0.05$ for $25 \mu \mathrm{M}$ $\mathrm{CdCl}_{2}$ vs. control). Significant increases of lactate dehydrogenase (LDH) activities in 10 and $25 \mu \mathrm{M} \mathrm{CdC1} 1_{2}$-exposed groups were observed $(\mathrm{p}<0.05$ and $\mathrm{p}<0.01$, respectively). A greatly decreased albumin content and a more malondialdehyde (MDA) formation also occurred after $\mathrm{CdCl}_{2}$ treatment. The $\mathrm{Ca}^{2+}$ concentrations in the culture medium of $\mathrm{CdCl}_{2}$-exposed hepatocytes were significantly decreased, while $\left[\mathrm{Ca}^{2+}\right]_{\mathrm{i}}$ appeared to be significantly elevated ( $\mathrm{p}<0.05$ or $\mathrm{p}<0.01$ vs. control). We found that in $\mathrm{Ca}^{2+}$-containing hydroxyethyl piperazine ethanesulfonic acid-buffered salt solution (HBSS) only, $\mathrm{CdCl}_{2}$ elicited $\left[\mathrm{Ca}^{2+}\right]_{\mathrm{i}}$ increases, which comprised an initially slow ascent and a strong elevated phase. However, in $\mathrm{Ca}^{2+}$-containing HBSS with addition of 2-aminoethoxydiphenyl borane (2-APB), $\mathrm{CdCl}_{2}$ caused a mild $\left[\mathrm{Ca}^{2+}\right]_{\mathrm{i}}$ elevation in the absence of an initial rise phase. Removal of extracellular $\mathrm{Ca}^{2+}$ showed that $\mathrm{CdCl}_{2}$ induced an initially slow $\left[\mathrm{Ca}^{2+}\right]_{\mathrm{i}}$ rise alone without being followed by a markedly elevated phase, but in a $\mathrm{Ca}^{2+}-$ free HBSS with addition of 2-APB, $\mathrm{CdCl}_{2}$ failed to elicit the $\left[\mathrm{Ca}^{2+}\right]_{i}$ elevation. These results suggest that abnormal $\mathrm{Ca}^{2+}$ homeostasis due to cadmium may be an important mechanism of the development of the toxic effect in murine hepatocytes. $\left[\mathrm{Ca}^{2+}\right]_{\mathrm{i}}$ elevation in acutely cadmium-exposed hepatocytes is closely related to the extracellular $\mathrm{Ca}^{2+}$ entry and an excessive release of $\mathrm{Ca}^{2+}$ from intracellular stores.
\end{abstract}

\section{Key words}

Cadmium $\bullet$ Toxicity $\bullet$ Hepatocyte $\bullet$ Calcium ion $\bullet$ Homeostasis

\section{Introduction}

Cadmium (Cd), is an extremely important industrial and environment pollutant, which results in the pollution of water, air and soil. It can accumulate in the bodies of plants and animals, and can enter the human body by food chain, followed by slow accumulation in the body. Such accumulation in many tissues and systems produces chronic and long-term pathogenic effects with multiple toxicity in various organs and cytotoxicity, such 
as hepatic injury, testicular damage, pulmonary edema, renal dysfunction, osteomalacia, development of cancer, etc. (Goering et al. 1995, Satarug et al. 2000, Lecoeur et al. 2002, Chen et al. 2003). It has been demonstrated that the major site of the initial cadmium accumulation and toxicity in the body is the liver (Elez et al. 2001). Our previous observations revealed that acute administration of cadmium to rats results in significant elevation of cadmium accumulation in the liver, testis and heart. Tenfold to 20-fold higher values were reported in the liver than in testes or heart, increasing proportionally to dosage used and time exposure to cadmium (Chen et al. 2003). Reports have been accumulated that cadmium can destroy the hepatic cell membrane and induce lipid peroxidation, affect the configuration and function of mitochondria and impair energy metabolism, damage DNA synthesis, transformation and expression (Koizumi et al. 1996, Risso-de Faverney et al. 2004, Hsiao and Stapleton 2004). Furthermore, there is evidence suggesting that changes of intracellular cation homeostasis are closely related to the mechanism of hepatic cell injury (Gasbarrini et al. 1992, Carini et al. 1995). Especially, the elevation of intracellular free $\mathrm{Ca}^{2+}$ concentration $\left(\left[\mathrm{Ca}^{2+}\right]_{\mathrm{i}}\right)$ is associated with the development of cell damage (Ueda et al. 2000, Orrenius et al. 1992). Cadmium can interfere for uptake with essential metal ions including calcium $(\mathrm{Ca})$, zinc $(\mathrm{Zn})$ and copper $(\mathrm{Cu})$, and especially affect $\mathrm{Ca}^{2+}$ signaling in hepatic cells (Blazka and Shaikh 1992, Dundjerski et al. 2000, Baker et al. 2003). Thus the effect of cadmium on intracellular $\mathrm{Ca}^{2+}$ homeostasis may be an important factor in the development of hepatocellular damage.

In the present study, to further clarify the hepatocellular toxicity and injury in Cd-exposed hepatocytes, hepatocyte viability and its malondialdehyde (MDA) content as well as lactate dehydrogenase (LDH) activity in cultured medium. were assayed. We also investigated the effect of cadmium on hepatocyte $\left[\mathrm{Ca}^{2+}\right]_{\mathrm{i}}$ under a laser scanning confocal microscope (LSCM) using Fluo-3/AM as an intracellular free $\mathrm{Ca}^{2+}$ fluorescent probe. In particular, we explored the effects of cadmium on $\mathrm{Ca}^{2+}$ signaling in hepatocytes to reveal its possible mechanisms.

\section{Material and Methods}

\section{Reagents}

HepatoZYME-SFM medium was from GIBCO (Invitrogen Co., USA) and type IV collagenase was purchased from Worthington Co., USA. 2-aminoethoxydiphenyl borane (2-APB) was obtained from Calbiochem Co., USA. Fluo-3/AM and Con A were from Fluka Co., USA. The ethylene glycol-bis ( $\beta$-amino ethyl ether)$\mathrm{N}, \mathrm{N}, \mathrm{N}$ '-tetraacetic acid (EGTA), hydroxyethyl piperazine ethanesulfonic acid (HEPES) and L-glutamine were from Amresco Co., USA. 3-[4,5-dimethylthiazol-2-yl]-2,5diphenyltetrazolium bromide (MTT) were from Sigma Chemical Co., USA. Cadmium chloride $\left(\mathrm{CdCl}_{2} \cdot 2.5 \mathrm{H}_{2} \mathrm{O}\right.$, analytical pure) was from Shanghai Tingxin Chemical Engineering Factory (Shanghai, China). Other chemicals were purchased from local commercial sources and were of analytical grade quality.

HEPES-buffered salt solution (HBSS) contained (mM): $\mathrm{NaCl} 135 ; \mathrm{KCl} 5 ; \mathrm{CaCl}_{2} 1.8 ; \mathrm{MgCl}_{2} 1$; HEPES 20; glucose 5 (pH 7.4). $\mathrm{Ca}^{2+}$-free HBSS contained no $\mathrm{Ca}^{2+}$ plus 1 mM EGTA.

\section{Isolation of hepatocytes}

ICR neonatal mice, 1-day-old, were obtained from the Experiment Animal Center of Nanjing Medical University, Nanjing, China. The mouse pups were sacrificed to collect livers under sterile conditions. The livers were quickly removed into an ice-cold D-Hank's solution ( $\mathrm{pH}$ 7.2) without $\mathrm{Ca}^{2+}$ and $\mathrm{Mg}^{2+}$ for washing, then minced into pieces with dissecting scissors, followed by placing the pieces in D-Hank's solution containing $0.03 \%$ Type IV collagenase for digestion of $10 \mathrm{~min}$ once at $37{ }^{\circ} \mathrm{C}$ and repeated until no liver tissue pieces were present. Cell suspensions were filtered through sterilized $150 \mu \mathrm{m}$ nylon membranes and washed in Hank's solution via two centrifugations at $1500 \mathrm{rpm}$ for $5 \mathrm{~min}$ after erythrocytes had been dissolved with $0.85 \%$ amchlor solution. Thereafter, the freshly isolated cells, whose viability exceeded $98 \%$ as stained by trypan blue exclusion, were hepatocytes which were diluted to $1 \times 10^{6}$ cells $/ \mathrm{ml}$ in HepatoZYME-SFM medium containing L-glutamine $(2 \mathrm{mM})$ and $100 \mathrm{U} / \mathrm{ml}$ penicillin/streptomycin for experiment of exposure to $\mathrm{CdCl}_{2}$ after preculture for $24 \mathrm{~h}$.

Assay for viability of administered $\mathrm{CdCl}_{2}$ in hepatocytes

Hepatocyte suspensions were seeded at $0.1 \mathrm{ml} /$ well in 96-well flat-bottomed plates and randomly divided into a normal control group and three groups treated with $\mathrm{CdCl}_{2}(5,10,25 \mu \mathrm{M}$, respectively) with six replicates of each group. Cells in the control group received D-Hank's solution at the same dose. The cultures were maintained for $12 \mathrm{~h}$ at $37{ }^{\circ} \mathrm{C}$ with $5 \% \mathrm{CO}_{2}$ 
humidified air. Then, $0.01 \mathrm{ml}(5 \mathrm{mg} / \mathrm{ml})$ of MTT reagent was added into each well and incubated for $4 \mathrm{~h}$. After the incubation, the incubation precipitates were dissolved with $0.1 \mathrm{ml}$ of SDS. The optical density (OD) values were measured by spectrophotometry at $570 \mathrm{~nm}$ using an ELx800 Microplate Reader (Bio-Tek Instruments, Inc. Winooski, Vermont, USA).

\section{Biochemical analysis of hepatocytes and culture medium after exposure to $\mathrm{CdCl}_{2}$}

Hepatocyte suspensions were seeded at $2 \mathrm{ml} /$ well in 6-well flat-bottomed plates and randomly divided into a normal control group and three treated groups with $\mathrm{CdCl}_{2}$ as described above. The specimens from hepatocytes and culture medium of each group were collected at $12 \mathrm{~h}$ after exposure to $\mathrm{CdCl}_{2}$. MDA and protein contents in the cells were assayed, and LDH and aspartate aminotransferase (AST) activities as well as albumin and $\mathrm{Ca}^{2+}$ contents in the culture medium, respectively, were detected by spectrophotometry using commercial kits (Nanjing Jiancheng Biotechnology Institute, China). The procedures indicated by the kits were performed strictly according to the manufacturer's protocol.

Laser scanning confocal microscope analysis of $\left[\mathrm{Ca}^{2+}\right]_{i}$ in $\mathrm{CdCl}_{2}$-exposed hepatocytes

The effect of $\mathrm{CdCl}_{2}$ exposure on $\left[\mathrm{Ca}^{2+}\right]_{\mathrm{i}}$ in hepatocytes were first evaluated. Fluo-3/AM was chosen to use as an intracellular free $\mathrm{Ca}^{2+}$ fluorescent probe for analysis of $\left[\mathrm{Ca}^{2+}\right]_{\mathrm{i}}$ in $\mathrm{CdCl}_{2}$-exposed living hepatocytes under LSCM. In short, 20- $\mu$ l samples of hepatocyte suspension were collected from each group $12 \mathrm{~h}$ after the experiment and loaded with $15 \mu \mathrm{l}$ of $40 \mu \mathrm{M}$ Fluo-3/AM for $30 \mathrm{~min}$ at $37{ }^{\circ} \mathrm{C}$, and then washed 3 times with D-Hank's solution to remove the extracellular Fluo-3/AM as described by Chen et al. (2005). To determine the $\left[\mathrm{Ca}^{2+}\right]_{\mathrm{i}}$ distribution in hepatocytes, LSCM analysis was performed with a Bio-Rad MRC 1024 laser scanning confocal imaging system (Bio-Rad, Cambridge, MA).

The parameters of LSCM were set up to a magnification $40 \mathrm{x}$, the excited light to $488 \mathrm{~nm}$, the emission light $522 / 35 \mathrm{~nm}$, the pinhole $10-40 \mathrm{~nm}$ and the power at $30 \%$. Thereafter, scan-time series menu was used to scan the hepatocytes repeatedly for monitoring the dynamic changes in $\left[\mathrm{Ca}^{2+}\right]_{\mathrm{i}}$ with green fluorescence. $\left[\mathrm{Ca}^{2+}\right]_{\mathrm{i}}$ levels were represented with fluorescent intensity (FI). Time series of optical sections through a cell was obtained with a XY-step. Total images were scanned in each experiment and the data were stored on disks for analysis.

To understand the possible mechanism of $\left[\mathrm{Ca}^{2+}\right]_{\mathrm{i}}$ alteration in $\mathrm{CdCl}_{2}$-treated hepatocytes, hepatocyte suspensions precultured for $24 \mathrm{~h}$ were loaded with Fluo3/AM, then washed and resuspended in $\mathrm{Ca}^{2+}$-containing HBSS or in $\mathrm{Ca}^{2+}$-free HBSS with/without $100 \mu \mathrm{M}$ of 2APB. This was followed by monitoring cellular $\left[\mathrm{Ca}^{2+}\right]_{\mathrm{i}}$ under LSCM as described above. After attaining stable values of $\left[\mathrm{Ca}^{2+}\right]_{\mathrm{i}}$ fluorescence, administration of $\mathrm{CdCl}_{2}$ $(10 \mu \mathrm{M})$ was performed with continuous recording at $2-\mathrm{s}$ intervals for $500 \mathrm{~s}$.

\section{Statistical analysis}

Data were represented as mean values \pm standard error. Statistical analysis was performed by Student's t-test (STATISTICA, Statsoft Inc., Tulsa, USA) on a conventional personal computer.

\section{Results}

Changes of AST and LDH activities as well as albumin and $\mathrm{Ca}^{2+}$ contents in culture medium of $\mathrm{CdCl}_{2}$-exposed hepatocytes

As shown in Figure 1a, AST activity increased in culture medium in hepatocytes administered $\mathrm{CdCl}_{2}$ and significantly higher activity $(\mathrm{p}<0.05)$ occurred in $25 \mu \mathrm{M} \mathrm{CdCl} 1_{2}$-treated group compared to that in control group. LDH activity in culture medium was higher in $\mathrm{CdCl}_{2}$-treated groups than in the control group and significantly higher values were found in 10 and $25 \mu \mathrm{M}$ $\mathrm{CdCl}_{2}$-treated groups ( $\mathrm{p}<0.05$ and $\mathrm{p}<0.01$, respectively) (Fig. 1b). A greatly decreased albumin content was observed after $\mathrm{CdCl}_{2}$ treatment (Fig. 1c). As demonstrated in Figure 1d, the $\mathrm{Ca}^{2+}$ concentrations in culture medium of $\mathrm{CdCl}_{2}$-exposed hepatocytes showed significant decreases compared to control cells $(\mathrm{p}<0.05$ or $\mathrm{p}<0.01)$.

Changes of viability and $M D A$ content in $C d C 1_{2}$-exposed hepatocytes

Administration of $\mathrm{CdCl}_{2}$ resulted in a dosedependent decrease of hepatocyte viability and a significantly lower value in $25 \mu \mathrm{M} \mathrm{CdC1} 1_{2}$-treated hepatocytes $(p<0.05)$ compared to that in control cells (Fig. 2a). The MDA content in $\mathrm{CdCl}_{2}$-treated hepatocytes greatly increased compared to that in control cells (Fig. 2b). 

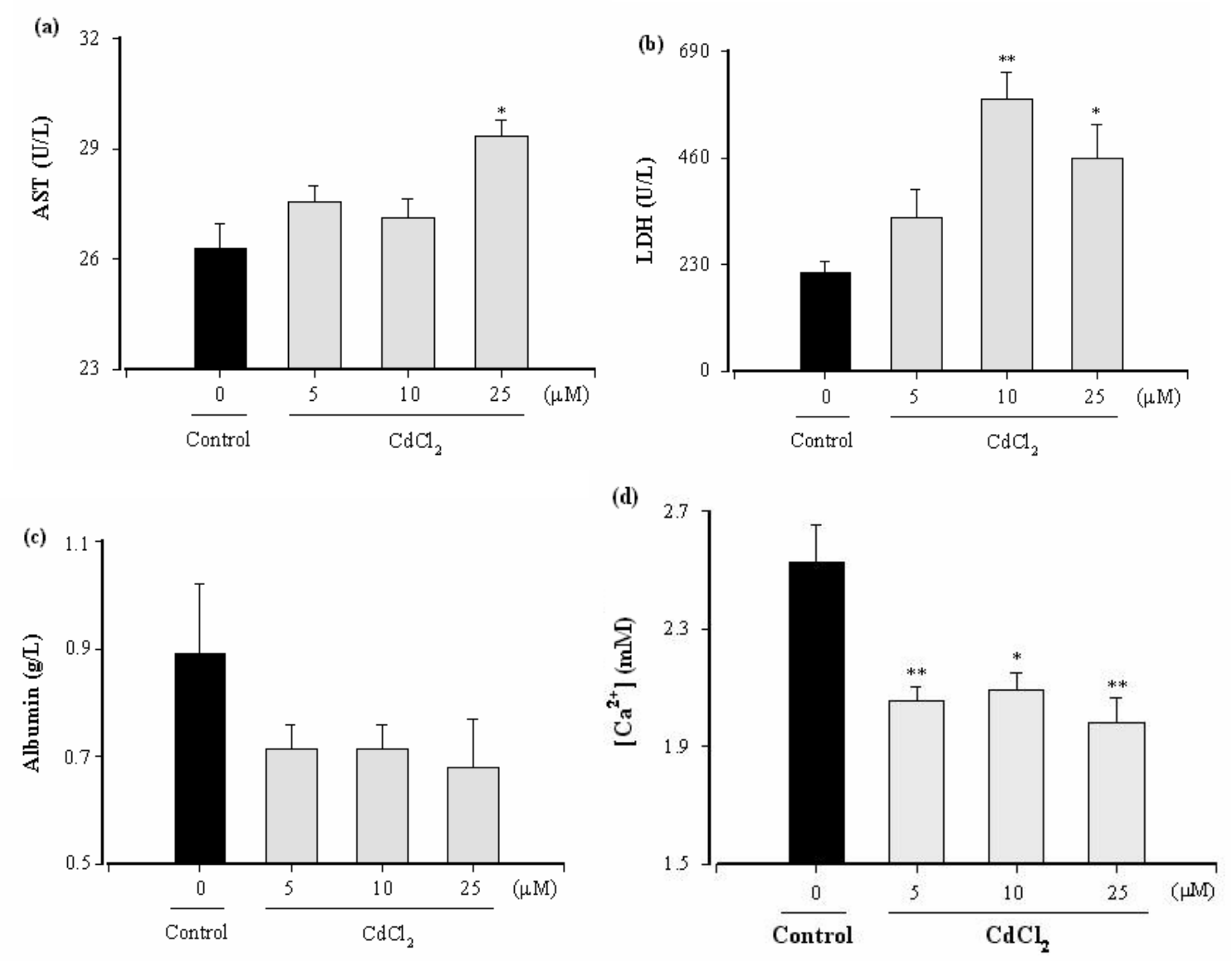

Fig. 1. Changes of AST and LDH activities as well as albumin and $\mathrm{Ca}^{2+}$ contents in culture medium of $\mathrm{CdC1}_{2}$-exposed murine hepatocytes. Primary murine hepatocytes were exposed to 5, 10, $25 \mu \mathrm{M} \mathrm{CdCl}_{2}$, respectively, and control cells received D-Hank's solution at the same dose. Spectrophotometry was used for biochemical analysis in culture medium. (a) changes of AST activity. (b) changes of LDH activity. (c) changes of albumin content. (d) changes of $\mathrm{Ca}^{2+}$ concentration. Results are presented as mean \pm S.E. ( $n=6$ ). $* \mathrm{p}<0.05, * * \mathrm{p}<0.01$ (Student's t-test). $\mathrm{CdCl}_{2}$ treatment groups vs. control group.
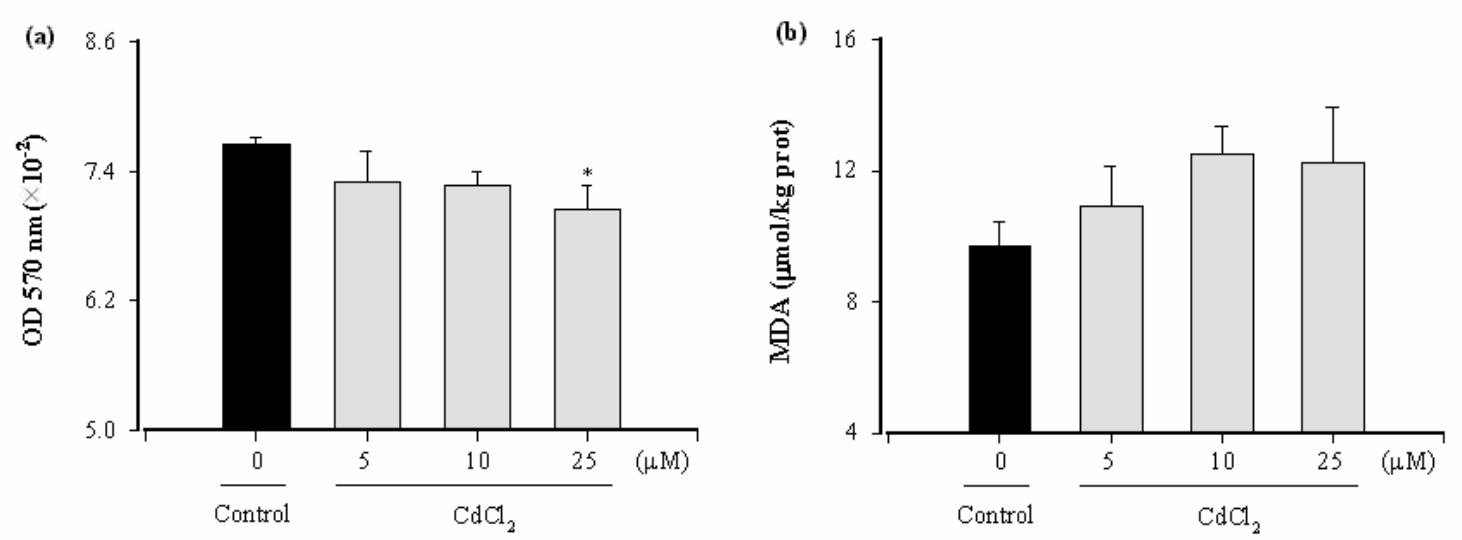

Fig. 2. Changes of viability and MDA content in $\mathrm{CdCl}_{2}$-exposed murine hepatocytes. (a) hepatocyte viability was evaluated using an MTT assay. (b) changes of MDA formation in hepatocytes was detected by spectrophotometry. Results are presented as mean \pm S.E. $(\mathrm{n}=6) . * \mathrm{p}<0.05$ (Student's t-test). $\mathrm{CdCl}_{2}$ treatment groups vs. control group.

Manifestation and changes of hepatocyte $\left[\mathrm{Ca}^{2+}\right]_{i}$ after exposure to $\mathrm{CdCl}_{2}$

Treatment of hepatocytes with $5-25 \mu \mathrm{M} \mathrm{CdCl}{ }_{2}$ altered hepatocyte $\left[\mathrm{Ca}^{2+}\right]_{i}$ handling, showing significantly stronger $\left[\mathrm{Ca}^{2+}\right]_{\mathrm{i}}$ fluorescent intensities at $12 \mathrm{~h}$ (panels $\mathrm{C}$, D, E vs. A, respectively) and $24 \mathrm{~h}$ (panels F, G, H vs. B, respectively) after the experiment under LSCM (Fig. 3a). Significantly higher $\left[\mathrm{Ca}^{2+}\right]_{\mathrm{i}}$ in $\mathrm{CdCl}_{2}$-treated hepatocytes 
(a)

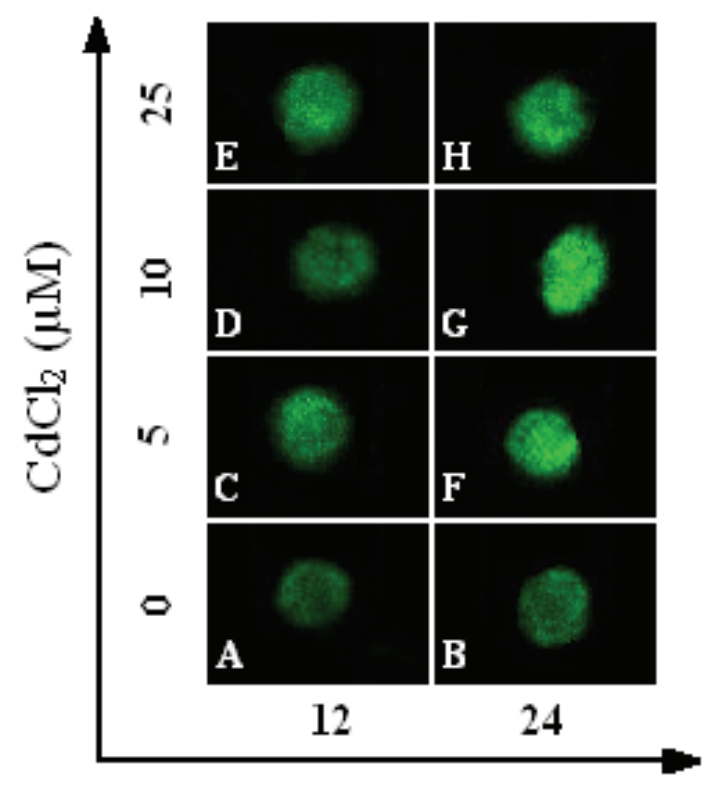

Time (h)

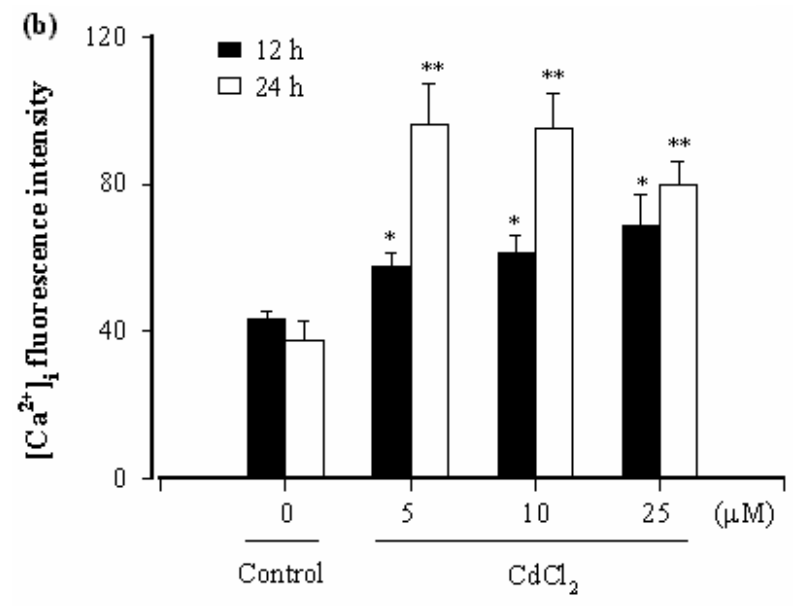

Fig. 3. $\left[\mathrm{Ca}^{2+}\right]_{\mathrm{i}}$ fluorescence visualizations and intensities in $\mathrm{CdC1}_{2}$-exposed murine hepatocytes. (a) Significantly stronger $\left[\mathrm{Ca}^{2+}\right]_{i}$ fluorescent visualizations at $12 \mathrm{~h}$ (photograph $\mathrm{C}, \mathrm{D}, \mathrm{E}$ vs. A, respectively) and $24 \mathrm{~h}$ (photograph $\mathrm{F}, \mathrm{G}, \mathrm{H}$ vs. B, respectively) after $5,10,25 \mu \mathrm{M} \mathrm{CdCl}_{2}$-exposed living hepatocytes, respectively, were evaluated, using a LSCM with fluorescent probe, Fluo-3/AM. (b) Changes of $\left[\mathrm{Ca}^{2+}\right]_{i}$ fluorescence intensities in hepatocytes after exposure to $\mathrm{CdCl}_{2}$. Results are presented as mean $\pm \mathrm{S}$.E. $(\mathrm{n}=6) . * \mathrm{p}<0.05, * * \mathrm{p}<0.01$ (Student's t-test). $\mathrm{CdCl}_{2}$ treatment groups vs. control group.

than in control cells at $12 \mathrm{~h}$ and $24 \mathrm{~h}(\mathrm{p}<0.05$ or $\mathrm{p}<0.01)$ and a dose-dependent increase at $12 \mathrm{~h}$ after the experiment are shown in Figure 3b.

As shown in Figure 4, administration of $10 \mu \mathrm{M}$ $\mathrm{CdCl}_{2}$ to freshly precultured hepatocytes loaded with Fluo-3/AM was performed in $\mathrm{Ca}^{2+}$-containing HBSS with/without 2-APB and in $\mathrm{Ca}^{2+}$-free HBSS with/without
2-APB to further understand the effects of $\mathrm{CdCl}_{2}$ on $\mathrm{Ca}^{2+}$ signaling in hepatocytes. We observed that in $\mathrm{Ca}^{2+}$ containing HBSS without 2-APB, $\mathrm{CdCl}_{2}$ elicited $\left[\mathrm{Ca}^{2+}\right]_{\mathrm{i}}$ increases which comprised an initially slow rise (0-100 s) and a strongly elevated phase (100-378 s), followed by a slow decay at a high level (Fig. 4a). However, in $\mathrm{Ca}^{2+}$ containing HBSS with 2-APB, a membrane-permeable inhibitor of inositol triphosphate receptor $\left(\mathrm{IP}_{3} \mathrm{R}\right)$ (Braun et al. 2003), $\mathrm{CdCl}_{2}$ caused a mild $\left[\mathrm{Ca}^{2+}\right]_{\mathrm{i}}$ elevation of the absence of a slow rise phase (Fig. 4b). Removal of extracellular $\mathrm{Ca}^{2+}$ reduced $\mathrm{CdCl}_{2}$-induced $\left[\mathrm{Ca}^{2+}\right]_{\mathrm{i}}$ signals, showing a slow rise alone without a subsequent elevated phase (Fig. 4c). Furthermore, in $\mathrm{Ca}^{2+}$-free HBSS containing 2-APB, $\mathrm{CdCl}_{2}$ failed to elicit $\left[\mathrm{Ca}^{2+}\right]_{\mathrm{i}}$ elevation, which was similar to the consequence of administered DHank's solution instead of $\mathrm{CdCl}_{2}$ in hepatocytes (data not shown).

\section{Discussion}

In this study, our group has shown that the administration of $\mathrm{CdCl}_{2}$ resulted in a dose-dependent decrease of murine hepatocyte viability and an elevated AST activity in the culture medium at 5-25 $\mu \mathrm{M}(\mathrm{p}<0.05$ for $25 \mu \mathrm{M} \mathrm{CdCl}_{2} v s$. control). LDH activity in the culture medium for hepatocytes exposed to $\mathrm{CdCl}_{2}$ was greatly enhanced and significantly higher values were observed in 10 and $25 \mu \mathrm{M} \mathrm{CdC1} 1_{2}$-exposed groups $(\mathrm{p}<0.05$ and $\mathrm{p}<0.01$, respectively), which is consistent with previous findings showing that cadmium induces the increase in LDH leakage as a sensitive indicator of cytotoxicity (Martel et al. 1990, Sarkar et al. 1995). Furthermore, a greatly decreased albumin content also occurred after $\mathrm{CdCl}_{2}$ treatment, indicating a decline of hepatic cell function (Doumas and Peters et al. 1997, Peters 1985). Reports have been accumulated that cadmium can destroy hepatic cell membranes and induce lipid peroxidation, thereby affecting the configuration and function of mitochondria and disturbing energy metabolism, impairing DNA synthesis, transformation and expression (Koizumi et al. 1996, Risso-de Faverney et al. 2004, Hsiao and Stapleton 2004). Previous studies of Stacey et al. (1980) have demonstrated that cadmium can lead to lipid peroxidation in isolated rat hepatocytes. However, Manzl et al. (2003) reported that cadmium does not cause acute short-term toxic effects in hepatocytes from the rainbow trout, Oncorhynchus mykiss. Our present study has shown greater MDA formation in $\mathrm{CdCl}_{2}$-exposed murine hepatocytes than in control cells, suggesting that 
(a)

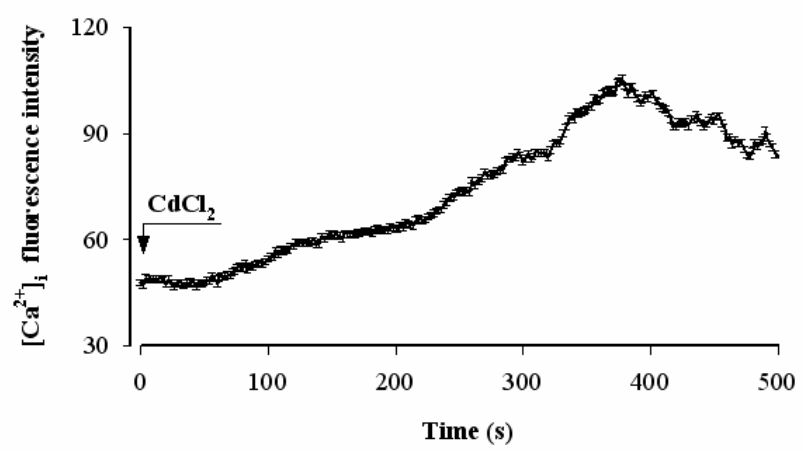

(b)

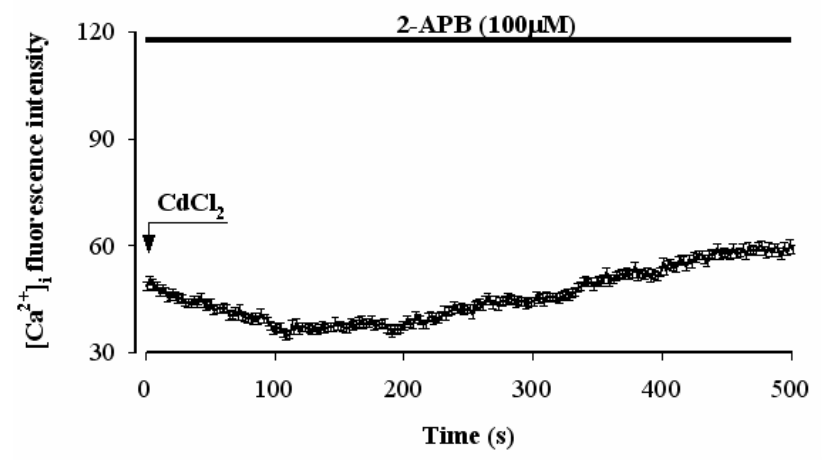

(c)

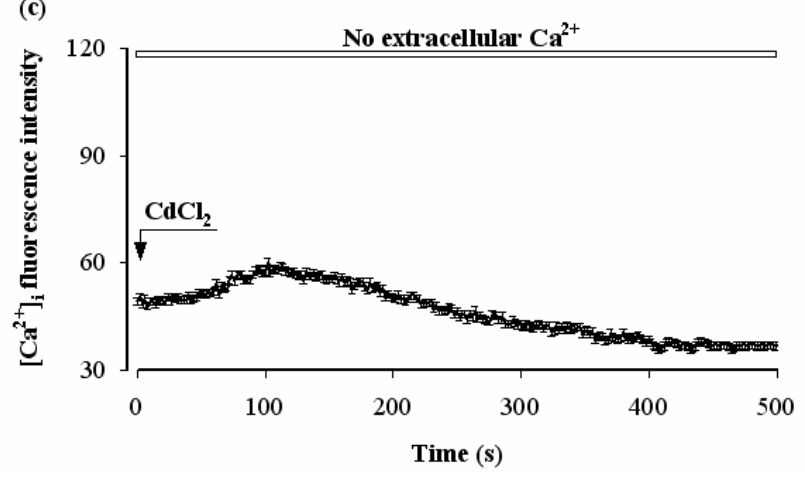

Fig. 4. Dynamic $\left[\mathrm{Ca}^{2+}\right]_{i}$ changes of acutely administered $\mathrm{CdCl}_{2}$ in in vitro murine hepatocytes. Primary murine hepatocytes were loaded with Fluo-3/AM, then washed and resuspended in $\mathrm{Ca}^{2+}$ containing HBSS or in $\mathrm{Ca}^{2+}$-free HBSS with/without $100 \mu \mathrm{M}$ of 2$\mathrm{APB}$, followed by monitoring cellular $\left[\mathrm{Ca}^{2+}\right]_{i}$ of administered $\mathrm{CdCl}_{2}$ $(10 \mu \mathrm{M})$ under LSCM. (a) In $\mathrm{Ca}^{2+}$-containing HBSS only, $\left[\mathrm{Ca}^{2+}\right]_{\mathrm{i}}$ increases which comprised an initially slow ascent and a strongly elevated phase. (b) In $\mathrm{Ca}^{2+}$-containing HBSS with addition of 2APB, a mild $\left[\mathrm{Ca}^{2+}\right]_{i}$ elevation was present without the initial rise. (c) In $\mathrm{Ca}^{2+}$-free HBSS only, an initially slow $\left[\mathrm{Ca}^{2+}\right]_{i}$ rise alone without following by a strong elevated phase. Results are presented as mean \pm S.E.M. $(n=6-12)$.

an enhanced lipid peroxidation reaction of hepatocytes exposed to cadmium does exist. Taken together, such findings reveal that acute administration of $\mathrm{CdCl}_{2}$ to in vitro murine hepatocytes results in a strongly toxic effect by inducing cellular lipid peroxidation and injury, thereby eliciting its decreased viability and malfunction.

Earlier studies have indicated that changes of intracellular cation homeostasis are closely related to the mechanism of hepatic cell injury (Gasbarrini et al. 1992, Carini et al. 1995). Especially, the $\left[\mathrm{Ca}^{2+}\right]_{\mathrm{i}}$ elevation is associated with the development of cell damage (Orrenius et al. 1992, Ueda et al. 2000). Cadmium can interfere for uptake with essential metal ions, such as $\mathrm{Ca}^{2+}, \mathrm{Zn}^{2+}$ and $\mathrm{Cu}^{2+}$, and especially affect $\mathrm{Ca}^{2+}$ signaling in hepatocytes (Blazka and Shaikh 1992, Dundjerski et al. 2000, Baker et al. 2003). In this study, Fluo-3/AM was chosen to use as an intracellular free $\mathrm{Ca}^{2+}$ fluorescent probe to evaluate the effect of cadmium on $\left[\mathrm{Ca}^{2+}\right]_{i}$ in murine hepatocytes. Digital imaging of living mussel hemocytes loaded with Fura-2/AM or Fluo-3/AM demonstrated that $\mathrm{Cd}^{2+}$ induced rise in probe fluorescence (Marchi et al. 2000). In particular, $\mathrm{Cd}^{2+}$ produced the strongest probe signal rise in free solution, but the lowest fluorescence increase in cells, indicating that Fura-2/AM or Fluo-3/AM can be a suitable tool to record the effect of $\mathrm{Cd}^{2+}$ on $\left[\mathrm{Ca}^{2+}\right]_{i}$ in living cells. However, in the presence of cadmium Fura$2 / \mathrm{AM}$ it is impossible to calibrate the $\left[\mathrm{Ca}^{2+}\right]_{\mathrm{i}}$ measurements conducted with cell suspension (Manzl et al. 2003). Recently, further reports indicated that Fura2/AM can be used in determination of intracellular $\mathrm{Cd}^{2+}$ level due to its very high affinity for $\mathrm{Cd}^{2+}$ (Le et al. 2005). Thus Fluo-3/AM, but not Fura-2/AM, was chosen for LSCM analysis of $\left[\mathrm{Ca}^{2+}\right]_{\mathrm{i}}$ in Cd-exposed hepatocytes. We observed that treatment of hepatocytes with 5-25 $\mu \mathrm{M}$ $\mathrm{CdCl}_{2}$ resulted in abnormal hepatocyte $\left[\mathrm{Ca}^{2+}\right]_{\mathrm{i}}$ handling, showing that significantly higher $\left[\mathrm{Ca}^{2+}\right]_{\mathrm{i}}$ was present in $\mathrm{CdCl}_{2}$-treated hepatocytes than in control cells at $12 \mathrm{~h}$ and $24 \mathrm{~h}$ after the experiment $(\mathrm{p}<0.05$ or $\mathrm{p}<0.01)$. This fact suggests that abnormal $\mathrm{Ca}^{2+}$ homeostasis due to cadmium may be an important mechanism of the development of hepatocellular damage.

Martinez-Sánchez et al. (2004) have reported that cells regulate their $\mathrm{Ca}^{2+}$ homeostasis by a complex interplay between three cellular mechanisms: $\mathrm{Ca}^{2+}$ influx and efflux through the plasma membrane, $\mathrm{Ca}^{2+}$ uptake and release from intracellular stores and intracellular $\mathrm{Ca}^{2+}$ buffering. $\left[\mathrm{Ca}^{2+}\right]_{\mathrm{i}}$ increase is usually caused by $\mathrm{Ca}^{2+}$ mobilization from intracellular stores and/or $\mathrm{Ca}^{2+}$ entry from the extracellular space (Jan et al. 2001). Our current study revealed that the $\mathrm{Ca}^{2+}$ concentrations in the culture medium of $\mathrm{CdCl}_{2}$-exposed hepatocytes were significantly lower, whereas there appeared significant $\left[\mathrm{Ca}^{2+}\right]_{\mathrm{i}}$ elevations in $\mathrm{CdCl}_{2}$-exposed hepatocytes compared to those in control cells $(p<0.05$ or $p<0.01$ ). This suggests that a part of $\left[\mathrm{Ca}^{2+}\right]_{\mathrm{i}}$ elevation may be closely related to extracellular $\mathrm{Ca}^{2+}$ entry after $\mathrm{CdCl}_{2}$ treatment. 
To better understand the effects of cadmium on $\left[\mathrm{Ca}^{2+}\right]_{\mathrm{i}}$ signaling in isolated living murine hepatocytes and to provide diverse information for clarifying the mechanism of $\mathrm{Cd}$-induced hepatotoxicity, the present study further investigated the dynamic $\left[\mathrm{Ca}^{2+}\right]_{\mathrm{i}}$ changes after in vitro administration of $\mathrm{CdCl}_{2}$ to murine hepatocytes which occurred in $\mathrm{Ca}^{2+}$-containing HBSS or in $\mathrm{Ca}^{2+}$-free HBSS with/without $100 \mu \mathrm{M}$ of 2-APB. We found that in $\mathrm{Ca}^{2+}$-containing HBSS only, administration of $\mathrm{CdCl}_{2}$ elicited $\left[\mathrm{Ca}^{2+}\right]_{i}$ increases which comprised an initially slow ascent and a subsequent strongly elevated phase, which were followed by a slow decay at a high level. However, in $\mathrm{Ca}^{2+}$-containing $\mathrm{HBSS}$ with the addition of 2-APB, $\mathrm{CdCl}_{2}$ caused a mild $\left[\mathrm{Ca}^{2+}\right]_{\mathrm{i}}$ elevation without an initial $\left[\mathrm{Ca}^{2+}\right]_{\mathrm{i}}$ rise, suggesting that the initial rise may be due to the release of $\mathrm{Ca}^{2+}$ from intracellular stores. It is evident that 2-APB, a membrane-permeable inhibitor of $\mathrm{IP}_{3} \mathrm{R}$ which plays a key role in $\mathrm{Ca}^{2+}$ release from endoplasmic reticulum (ER) (Hajnóczky and Thomas 1997), has extensively been used to investigate the effects of $\mathrm{IP}_{3}$-induced $\mathrm{Ca}^{2+}$ release and $\mathrm{Ca}^{2+}$ influx in a number of cell systems (Bilmen et al. 2002, Braun et al. 2003). and also appears to be an inhibitor of capacitative calcium entry channels (Ma et al. 2000, Broad et al. 2001, Gregory et al. 2001). Thus blocking the $\mathrm{IP}_{3} \mathrm{R}$ by 2-APB may abolish the initial $\mathrm{Ca}^{2+}$ release from ER and affect the following $\mathrm{Ca}^{2+}$ influx from extracellular space, leading thus to a mild $\left[\mathrm{Ca}^{2+}\right]_{i}$ elevation. The latter effect may also be partly due to the inhibition of corresponding $\mathrm{Ca}^{2+}$-influx channels by 2-APB (Ma et al. 2000).

Our further observations showed that the removal of extracellular $\mathrm{Ca}^{2+}$ reduced $\mathrm{CdCl}_{2}$-induced $\left[\mathrm{Ca}^{2+}\right]_{\mathrm{i}}$ signals, showing an initially slow $\left[\mathrm{Ca}^{2+}\right]_{\mathrm{i}}$ rise alone without a subsequent strongly elevated phase. On the other hand, in $\mathrm{Ca}^{2+}$-free HBSS with addition of 2APB, $\mathrm{CdCl}_{2}$ failed to elicit any $\left[\mathrm{Ca}^{2+}\right]_{\mathrm{i}}$ elevation (including an initially slow rise) during the entire experiment period, which was similar to a consequence of administered D-Hank's instead of $\mathrm{CdCl}_{2}$ in hepatocytes (data not displayed). These findings strongly support our assumption that a major part of $\left[\mathrm{Ca}^{2+}\right]_{i}$ elevation in $\mathrm{CdCl}_{2}$-exposed hepatocytes deals with the extracellular $\mathrm{Ca}^{2+}$ entry, whereas the initial segment of $\left[\mathrm{Ca}^{2+}\right]_{\mathrm{i}}$ elevation induced by $\mathrm{CdCl}_{2}$ is associated with an excessive release of $\mathrm{Ca}^{2+}$ from intracellular stores.

In conclusion, the main finding of this study is that abnormal $\mathrm{Ca}^{2+}$ homeostasis due to cadmium may be an important mechanism in the development of toxic effect in murine hepatocytes. $\left[\mathrm{Ca}^{2+}\right]_{\mathrm{i}}$ elevation in acutely cadmium-exposed hepatocytes is closely related to the extracellular $\mathrm{Ca}^{2+}$ entry and the excessive release of $\mathrm{Ca}^{2+}$ from intracellular stores.

\section{Acknowledgements}

This work was supported by a Special Foundation from Jiangsu Province Key Laboratory for Resource Biotechnology, P.R. China (No. KJS02022), and the funding from Jiangsu Engineering Research Center for Bio-medical Function Materials, P.R. China. We thank Dr. C.Y. Zhang for the help and technical support in LSCM analysis.

\section{References}

BAKER TK, VANVOOREN HB, SMITH WC, CARFAGNA MA: Involvement of calcium channels in the sexual dimorphism of cadmium-induced hepatotoxicity. Toxicol Lett 137: 185-192, 2003.

BILMEN JG, WOOTTON LL, GODFREY RE, SMART OS, MICHELANGELI F: Inhibition of SERCA Ca ${ }^{2+}$ pumps $^{2}$ by 2-aminoethoxydiphenyl borate (2-APB). 2-APB reduces both $\mathrm{Ca}^{2+}$ binding and phosphoryl transfer from ATP, by interfering with the pathway leading to the $\mathrm{Ca}^{2+}$-binding sites. Eur J Biochem 269: 3678-3687, 2002.

BLAZKA ME, SHAIKH ZA: Cadmium and mercury accumulation in rat hepatocytes: interactions with other metal ions. Toxicol Appl Pharmacol 113: 118-125, 1992.

BRAUN FJ, AZIZ O, PUTNEY JW JR: 2-aminoethoxydiphenyl borane activates a novel calcium-permeable cation channel. Mol Pharmacol 63: 1304-1311, 2003.

BROAD LM, BRAUN FJ, LIEVREMONT JP, BIRD GS, KUROSAKI T, PUTNEY JW Jr: Role of the phospholipase $\mathrm{C}$-inositol 1,4,5-trisphosphate pathway in calcium release-activated calcium current and capacitative calcium entry. J Biol Chem 276: 15945-15952, 2001.

CARINI R, BELLOMO G, BENEDETTI A, FULCERI R, GAMBERUCCI A, PAROLA M, DIANZANI MU, ALBANO E: Alteration of $\mathrm{Na}^{+}$homeostasis as a critical step in the development of irreversible hepatocyte injury after adenosine triphosphate depletion. Hepatology 21: 1089-1098, 1995. 
CHEN L, ZHOU J, GAO W, JIANG YZ: Action of NO and TNF- $\alpha$ release of rats with cadmium loading in mediating malfunction of multiple system organs. Acta Physiol Sin 55: 535-540, 2003.

CHEN L, PAN DD, ZHOU J, JIANG YZ: Protective effect of selenium-enriched lactobacillus on $\mathrm{CCl}_{4}$-induced liver injury in mice and its possible mechanisms. World J Gastroenterol 11: 5795-5800, 2005.

DOUMAS BT, PETERS T JR: Serum and urine albumin: a progress report on their measurement and clinical significance. Clin Chim Acta 258: 3-20, 1997.

DUNDJERSKI J, KOVAC T, PAVKOVIC N, CVORO A, MATIC G: Glucocorticoid receptor-Hsp90 interaction in the liver cytosol of cadmium-intoxicated rats. Cell Biol Toxicol 16: 375-383, 2000.

ELEZ D, DUNDJERSKI J, MATIC G: Cadmium affects the redox state of rat liver glucocorticoid receptor. Cell Biol Toxicol 17: 169-177, 2001.

GASBARRINI A, BORLE AB, FARGHALI H, BENDER C, FRANCAVILLA A, VAN THIEL D: Effect of anoxia on intracellular ATP, $\mathrm{Na}^{+}{ }_{\mathrm{i}}, \mathrm{Ca}^{2+}{ }_{\mathrm{i}}, \mathrm{Mg}^{2+}{ }_{\mathrm{i}}$, and cytotoxicity in rat hepatocytes. J Biol Chem 267: 6654-6663, 1992.

GOERING PL, WAALKES MP, KLAASSEN CD: Toxicology of cadmium. In: Toxicology of Metals: Biochemical Aspects, Handbook of Experimental Pharmacology. GOYER RA, CHERIAN MG, (eds), Springer, New York, 1995, pp 189-213.

GREGORY RB, RYCHKOV G, BARRITT GJ: Evidence that 2-aminoethyl diphenylborate is a novel inhibitor of storeoperated $\mathrm{Ca}^{2+}$ channels in liver cells, and acts through a mechanism which does not involve inositol trisphosphate receptors. Biochem J 354: 285-290, 2001.

HAJNÓCZKY G, THOMAS AP: Minimal requirements for calcium oscillations driven by the $\mathrm{IP}_{3}$ receptor. $E M B O J$ 16: 3533-3543, 1997.

HSIAO CJ, STAPLETON SR: Characterization of Cd-induced molecular events prior to cellular damage in primary rat hepatocytes in culture: activation of the stress activated signal protein JNK and transcription factor AP-1. J Biochem Mol Toxicol 18: 133-142, 2004.

JAN CR, CHENG JS, ROAN CJ, LEE KC, CHEN WC, CHOU KJ, TANG KY, WANG JL: Effect of diethylstilbestrol (DES) on intracellular $\mathrm{Ca}^{2+}$ levels in renal tubular cells. Steroids 66: 505-510, 2001.

KOIZUMI T, SHIRAKURA H, KUMAGAI H, TATSUMOTO H, SUZUKI KT: Mechanism of cadmium-induced cytotoxicity in rat hepatocytes: cadmium-induced active oxygen-related permeability changes of the plasma membrane. Toxicology 114: 125-134, 1996.

LE HD, OMELCHENKO A, HRYSHKO LV, ULIYANOVA A, CONDRESCU M, REEVES JP: Allosteric activation of sodium-calcium exchange by picomolar concentrations of cadmium. J Physiol Lond 563: 105-117, 2005.

LECOEUR S, HUYNH-DELERME C, BLAIS A, DUCHE A, TOME D, KOLF-CLAUW M: Implication of distinct proteins in cadmium uptake and transport by intestinal cells HT-29. Cell Biol Toxicol 18: 409-423, 2002.

MA HT, PATTERSON RL, VAN ROSSUM DB, BIRNBAUMER L, MIKOSHIBA K, GILL DL: Requirement of the inositol trisphosphate receptor for activation of store-operated $\mathrm{Ca}^{2+}$ channels. Science 287: 1647-1651, 2000.

MANZL C, EBNER H, KOCK G, DALLINGER R, KRUMSCHNABEL G: Copper, but not cadmium, is acutely toxic for trout hepatocytes: short-term effects on energetics and ion homeostasis. Toxicol Appl Pharmacol 191: 235244, 2003.

MARCHI B, BURLANDO B, PANFOLI I, VIARENGO A: Interference of heavy metal cations with fluorescent $\mathrm{Ca}^{2+}$ probes does not affect $\mathrm{Ca}^{2+}$ measurements in living cells. Cell Calcium 28: 225-231, 2000.

MARTEL J, MARION M, DENIZEAU F: Effect of cadmium on membrane potential in isolated rat hepatocytes. Toxicology 60: 161-172, 1990.

MARTINEZ-SÁNCHEZ M, STRIGGOW F, SCHRODER UH, KAHLERT S, REYMANN KG, REISER G: $\mathrm{Na}^{+}$and $\mathrm{Ca}^{2+}$ homeostasis pathways, cell death and protection after oxygen-glucose-deprivation in organotypic hippocampal slice cultures. Neuroscience 128: 729-740, 2004.

ORRENIUS S, MCCABE MJ JR, NICOTERA P: $\mathrm{Ca}^{2+}$-dependent mechanisms of cytotoxicity and programmed cell death. Toxicol Lett 64-65: 357-364, 1992.

PETERS T JR: Serum albumin. Adv Protein Chem 37: 161-245, 1985.

RISSO-DE FAVERNEY C, ORSINI N, DE SOUSA G, RAHMANI R: Cadmium-induced apoptosis through the mitochondrial pathway in rainbow trout hepatocytes: involvement of oxidative stress. Aquat Toxicol 69: 247$258,2004$. 
SARKAR S, YADAV P, TRIVEDI R, BANSAL AK, BHATNAGAR D: Cadmium-induced lipid peroxidation and the status of the antioxidant system in rat tissues. J Trace Elem Med Biol 9: 144-149, 1995.

SATARUG S, HASWELL-ELKINS MR, MOORE MR: Safe levels of cadmium intake to prevent renal toxicity in human subjects. Br J Nutr 84: 791-802, 2000.

STACEY NH, CANTILENA LR Jr, KLAASSEN CD: Cadmium toxicity and lipid peroxidation in isolated rat hepatocytes. Toxicol Appl Pharmacol 53: 470-480, 1980.

UEDA T, TAKEYAMA Y, HORI Y, TAKASE K, GOSHIMA M, KURODA Y: Pancreatitis-associated ascitic fluid increases intracellular $\mathrm{Ca}^{2+}$ concentration on hepatocytes. J Surg Res 93: 171-176, 2000.

\section{Corresponding author}

L. Chen, College of Life Sciences, Nanjing Normal University, 122 Ninghai Road, Nanjing, Jiangsu, P.R. China, 210097. Fax: +86-25-83598723. E-mail: lchen@njnu.edu.cn (L. Chen) 